\title{
The Finnish Pension Reform of $2005^{*}$
}

\author{
Jukka Lassila and Tarmo Valkonen \\ ETLA, Lönnrotinkatu 4 B, Helsinki, FI-00120, Finland. \\ E-mails: jla@etla.fi, tv@etla.fi
}

A major reform in the Finnish private-sector earnings-related pension system came into effect on 1st January, 2005. It was negotiated in 2001-2002 between the central organisations of employers and trade unions and representatives of the central government. This paper describes the reform and analyses its effects on selected macroeconomic variables, on the pension system and on the position of different birth cohorts and different educational groups. The reform appears to be successful in many respects. It simplifies the private-sector pension system and makes it a model that other pension systems in Finland will converge to. The reform rewards postponing retirement. It curbs the increase in contribution rate without endangering the adequacy of replacement rates. The increase in labour supply will have beneficial welfare effects. The new system also responds rather well to uncertain future demographics. Despite this apparent success of the reform there remains a serious doubt of its adequacy, as contribution rates are still expected to rise by several percentage points.

The Geneva Papers (2007) 32, 75-94. doi:10.1057/palgrave.gpp.2510108

Keywords: pension reform; population ageing; stochastic population simulations

JEL classification: H55; J11

\section{Introduction}

A major reform of the Finnish private-sector earnings-related pension system was agreed on in 2001-2002. The agreement was justified by the need to mitigate rising pension costs due to population ageing, similar to arguments spurring many other recent reforms in Europe. The large reform package consists of an interesting combination of measures that were expected to improve both the economic and social sustainability of the pension system.

The main aims of the reform are to postpone the average retirement age, curb the expected increases in contribution rates and to support ageing workers' ability to cope with their work. A further initial and widely supported target was to simplify the pension rules and make them both more transparent and more actuarial. The first aim is promoted by rewarding continued participation in working life and by restricting

\footnotetext{
* The paper is part of the European Commission's research project "Demographic uncertainty and the sustainability of social welfare systems" (QLK6-CT-2002-02500). We also acknowledge the financial support from the Ministry of Social Affairs and Health and the Finnish Centre for Pensions. We are grateful to Heikki Palm for the advice and support. We also thank Peter Biström, Anthony de Carvalho, Seija Ilmakunnas, Niku Määttänen, Juha Rantala, Ismo Risku, Eila Tuominen, Reijo Vanne and an anonymous referee for comments and Eija Kauppi for the model programming.
} 
access to early retirement schemes. In addition to the benefits gained from later retirement, the reform strengthens financial sustainability by starting to apply life expectancy adjustment to the accrued pension rights.

The agreement was a compromise between central organisations of employers and trade unions and representatives of the central government. Interestingly, the main disagreements were between various trade unions. ${ }^{1}$ In addition to preserving the vested interests of the unions, some details of the agreement reflect the aim of protecting the generations near retirement from abrupt changes in pension rules. The reform has been analysed earlier with an actuarial model by Biström et $a l^{2}$ and verbally by Börsch-Supan. ${ }^{3}$ The longer policy line of fostering employment among older workers in Finland has been discussed in depth by Ilmakunnas and Takala. ${ }^{4}$

We analyse the reform using a numerical modelling framework, which allows us to simulate the interaction of the changed pension rules, households' reactions to those changes and the adjustment process in various markets of the economy. We first aim to give an extensive view of the expected effects of the reform in terms of macroeconomic outcomes, pension system variables and household incomes by birth cohort and education. The sustainability aspect is assessed by using a large amount of sample populations from a stochastic population forecast as inputs in the economic model, thereby creating probability-based descriptions for future paths of the contribution and replacement rates.

A similar type of numerical overlapping generations model has been used to analyse pension reforms by, for example, Kotlikoff et $a .^{5}{ }^{5}$ and Fehr. ${ }^{6}$ The method of analysing both financial and social sustainability with stochastic population simulations was earlier used by Alho et al. ${ }^{7}$ in a study of the Lithuanian pension system.

The remainder of the paper is organised as follows. The following section presents the Finnish pension system and the changes it will likely undergo as a result of the reform. The next section describes the methods we use. Then we describe the expected impacts of the reform. In the penultimate section, demographic uncertainty and its consequences for the risks faced by workers and pensioners are discussed. Concluding comments are provided in the last section.

\section{Description and general assessment of the private sector pension reform}

The Finnish pension system consists of two main parts. The earnings-related pension system aims to provide retirement income sufficient to cover consumption comparable to levels enjoyed during working years and to current workers' consumption. It covers risks related to old age, disability, long-term unemployment of ageing workers, and

\footnotetext{
${ }^{1}$ See Lassila (2004).

2 Biström et al. (2004).

${ }^{3}$ Börsch-Supan (2005).

${ }^{4}$ Ilmakunnas and Takala (2005).

${ }^{5}$ Kotlikoff et al. (1998).

${ }^{6}$ Fehr (2000).

${ }^{7}$ Alho et al. (2005).
} 
death of family earners. The national pension guarantees a minimum income in cases where the earnings-related pension is absent or insufficient. Both these first pillar systems are mandatory. Voluntary pensions, whether employer-based or industry-wide supplementary pensions (second pillar) or personal pension arrangements (third pillar), are becoming more common but still of minor importance in Finland.

The Finnish earnings-related system is statutory by law but largely privately run. It has collected substantial funds to smoothen the contribution increases due to population ageing in the future. Funding is collective but based on individual pension rights. Individual pension benefits do not depend on the existence or yield of funds. Funds only affect contributions. When a person receives pensions after the age of 65 , his funds are used to pay that part of the pension benefit that was prefunded. The rest comes from the PAYG part, the so-called pooled component in the contribution rate. A more detailed presentation of the system can be found in Hietaniemi and Vidlund. ${ }^{8}$

The latest major reform, agreed on in 2001-2002, mainly took effect from the beginning of 2005. The main aims of the pension reform are to reward continued participation in working life and postpone the average retirement age, to take increasing life expectancy into account, to curb the expected increases in contribution rates, and to support ageing workers' ability to cope with their work. The initial targets of social partners and the state were not explicitly stated before the negotiations, but reducing the expected future increases in contributions certainly was one target, and postponing retirement was considered as the main instrument or sub-target in achieving it. One initial and widely supported target was to simplify the pension rules and make them both more transparent and more actuarial. Below we describe the old system in some detail and depict and discuss changes brought by the reform.

Earlier every employment contract and self-employment period added to the pension after the age of 23. The pensionable wage was aggregated over the last 10 years of each contract. The accrued pension right was vested, even if one changed jobs or stopped working. Following the reform, accrual now starts at the age of 18. Instead of using employment contracts and the pensionable wage concept, every year's earnings and accrual rates directly affect the future pension (the career model).

The "target" level of benefits used to be 60 per cent of wages. This accrued in about 40 years: 1.5 per cent per year between ages 23 and 59 and 2.5 per cent per year between 60 and 65 . There was no upper absolute limit to benefits, but an upper percentage limit was 60 per cent of the highest pensionable earnings. The reform removed this ceiling. The accrual rate is 1.5 per cent per year between ages 18 and 53, 1.9 per cent per year between ages 53 and 62, and 4.5 per cent per year between ages 63 and 68 . The 4.5 per cent accrual rate is aimed to reward later retirement in a costneutral way.

Disagreements between different trade unions led to these different accrual rates for employees of different ages. The previous system favoured those with both long employment contracts and rising wage-age profiles, typically white-collar workers with higher salaries. For them, the whole accrual percentage was applied to the last high

\footnotetext{
${ }^{8}$ Hietaniemi and Vidlund (2003).
} 
wages of the career. Moving to a system where each year of the career weighs the same would weaken their relative position. The negotiated result was a compromise, where the latter years of the work career still matter more than the earlier years.

Pension rights and benefits are index-linked, previously with 50-50 weights on wages and consumer prices, respectively, during working years, and 20-80 weights after age 65. After the reform, the change in indexation takes place at actual retirement, irrespective of age. The respective weights before retirement are 80-20 and 20-80 after retirement. When wages over the entire career affect the pension, the role of indexing becomes more significant. A move from 50-50 to 80-20 weights on wages and consumer prices is likely to overcompensate for the effect that early career wages will be more important and late career wages less important than before the reform.

Contributions are collected from both employers (on average 16.8 per cent of wages in 2004) and employees (4.6 per cent). It was agreed to share future changes $50-50$ between employers and employees. After the reform, employees aged 53 and over pay contributions that are about 1.27 times higher than that of younger employees, reflecting their higher accrual. This increase in employee contribution rate does not suffice to finance their increased accrual, which in the future means higher contributions for both employers and all employees. This creates a generational effect: those reaching 53 in 2005 or thereabouts will benefit from the higher accrual but retire before it really affects the contribution rates.

The reform brought the Swedish-type longevity adjustment coefficient into the pension system. It will start cutting monthly pensions for all cohorts reaching the age of 62 in 2010 or later. The effects of such an adjustment in Finland had been previously considered in at least two studies. ${ }^{9}$ The last of these includes also generational effects. The effects depend on how much life expectancy will actually increase.

There has been some consensus among Finnish decision-makers that people should not retire as early as they now do. The target of raising the age of retirement currently ranks high on the agenda in the debate among pension policy experts in all European countries. Unfortunately, however, this proposal is very unpopular among citizens. A survey ${ }^{10}$ conducted in September-October 2001 showed that raising the retirement age is favoured by only 23 per cent of the public, while 69 per cent express disagreement (the rest do not know). The Finnish numbers were very close to these EU-15 averages. The average retirement age in Finland is currently somewhat below 60 years.

The reform introduced major changes to the pre-retirement pensions. The unemployment pension is gradually being abolished and the lower age limit for entitlement to continued unemployment allowance was increased. Also, age limits for the part-time pension and the early old-age pension were increased and the individual early retirement pension was abolished. The new flexible retirement on an old-age pension takes place between ages 62 and 68 .

Labour force participation rates of older people are likely to increase following the changes to the pre-retirement pensions in the pension reform. Also, the change in

\footnotetext{
${ }^{9}$ Lindell (1999); Alho (2003); and Lassila and Valkonen (2003).

${ }^{10}$ European Commission (2004).
} 
accrual rates for those over 62 provides better incentives to continue working for persons with short work career and thus little accrued pension wealth before the age of 62. For those with long work careers the abolishment of the accrual ceiling may be important. Longevity adjustment will perhaps on its part postpone retirement, especially as it has been marketed and described in terms of the number of extra months each cohort needs to work in order to cancel the adjustment effect on pension. Other changes in the system will also affect the incentives to work or retire, if people know them and take them rationally into account, but there are opposing income and substitution effects, so the net effects, remain uncertain.

The prefunding rules before the reform were as follows. A part of old-age pension benefits, payable after age 65, was funded for each employee. Funding took place between ages 23 and 55, so only benefits accrued during those years were (partially) funded. After the reform, the rules are otherwise similar, but prefunding starts at age 18. Also, some additional funding between 2003 and 2013 was decided, amounting to 7.5 per cent of the insured wage sum in 2013. Apparently, the trade unions demanded this temporary measure, at least partly to prevent a situation where current pension rules would have resulted in contributions being temporarily lower, followed by a sharp increase. The third change in funding is that the additional part in contributions, paid by employees aged 53 and over, is prefunded.

The reform also changed the accrual rates and eligibility to benefits based on some non-salary income (maternity, paternity and parent's allowance, earnings-related unemployment allowance and job alternation leave, sickness daily allowance, etc.). That part of the reform is financed by sources other than the pension contributions, which cover the rest of the system, and is not included in our analysis.

\section{The method}

The economic framework that we use is an open economy version of the well-known Auerbach-Kotlikoff-type numerical overlapping generations simulation model. ${ }^{11}$ The model consists of lifetime utility-maximising perfect foresight households, firms, foreign agents and a pension fund for both the private and public sector. The aggregate household sector consists of 14 contemporarily living (overlapping) 5-year birth cohorts of different ages and of three types of education (primary, secondary and tertiary). The dynamics of population ageing with births, deaths and migration, as well as the strong improvement in the educational structure of the Finnish population, is imitated closely with the model.

The households make forward-looking decisions about consumption, saving, labour supply and bequests. The rules of the pension system influence the lifetime plans via several channels. The pension contributions distort labour supply during the working career, but the effect is dampened by the earned pension accruals. The possibilities as well as the need to save for old age are reduced due to the paid contributions and received pensions.

\footnotetext{
${ }^{11}$ Auerbach and Kotlikoff (1987).
} 
The educational groups differ in the level and shape of their career earnings, their age when they enter the labour force, and when they retire. Entering and exiting the labour force takes place gradually, with those with only a basic education (and the lowest earnings) entering and retiring younger and those with better education and higher earnings entering and exiting later. Differences in mortality rates between educational groups are not taken into account in the calculations.

The model also generates new equilibrium price paths for labour, goods and capital markets and balances public sector expenditures and receipts with taxes after the reform. The changes in prices and taxes also affect the reactions of the households. The perfectly functioning labour markets of the model and the low elasticity of labour supply on wage changes imply that the incidence of the employers' contributions is mainly on labour. Wages adjust to keep the employer's total labour costs almost the same. Separating the actual payer of the pension contribution is in this case meaningful only from the point of view of the tax authorities.

A description of the whole adjustment path is essential, since the transition period in the pension reform is very long. A short overview of the model and the new pension rules are described in the Appendix. ${ }^{12}$

The key assumption in our analysis is that the reform will postpone retirement. Although this is a necessary assumption for our model set-up, it is a rather plausible one as the reform both rewards longer work careers fiscally and makes early retirement more difficult. We assume that the effective age of retirement increases by well over a year in 20 years time. This is in line with several independent estimates of the deferral of retirement.

The model is used to simulate the dynamic path of the economy before and after the pension reform and to compare the results. We get two types of results. The ones presented in the section Simulation Results are based on expected demographic development, and they correspond to official evaluations of the impacts of the reform. We provide additional information to those because our model incorporates the behavioural responses of households and markets to the reform.

The key numbers presented are the time paths of selected macroeconomic variables, the pension contribution and replacement rates, and generation-specific actuarity ratio. The actuarity ratio is the ratio of a cohort's discounted benefits from the pension system to its discounted sum of payments to the pension system. The benefits include old-age pensions, disability and unemployment pensions and all other pensions from the earnings-related pension system. A ratio of 100 means that the cohort receives just what it pays, and a ratio below (above) 100 means that it gets less (more) than it pays.

The second type of results, presented in the next section, assesses the interaction of demographic risks and the pension reform. We use 300 randomly chosen sample population paths from a stochastic population forecast to determine the size and age structure of the household sector. These datasets are used as inputs in the numerical OLG model. The corresponding 300 simulations provide us with data that can be used to describe the predictive distributions of the result variables. The predictive

\footnotetext{
12 The model has been described also in Lassila and Valkonen (2003); a detailed description is available from the authors.
} 


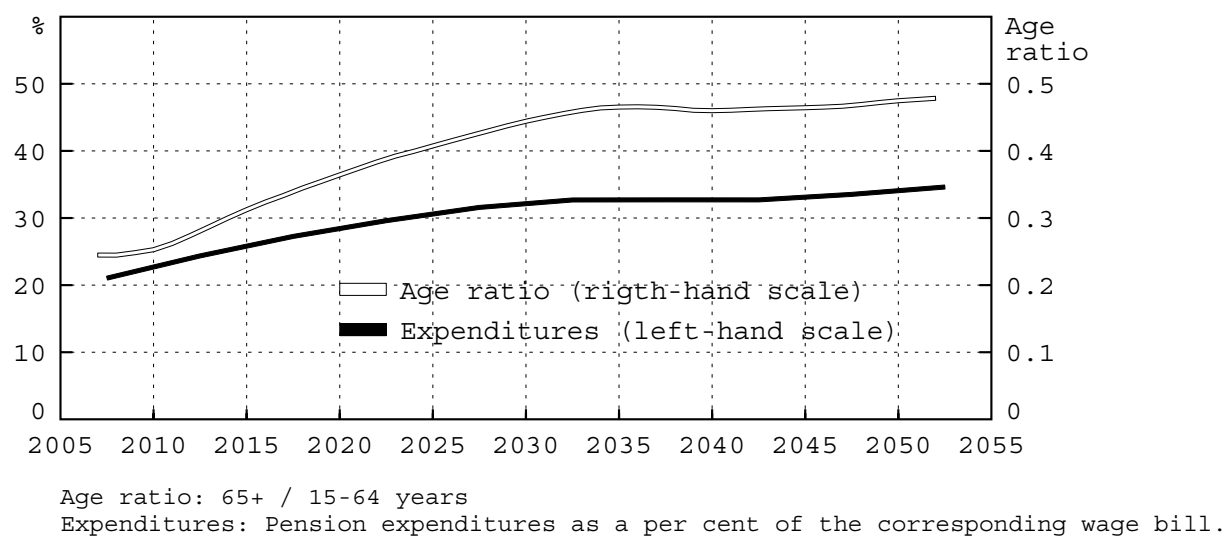

Figure 1. Projections of age ratio and private sector pension expenditures before the reform.

distribution of the contribution rate describes financial sustainability, the distribution of replacement rate and the social sustainability of the new system with respect to demographic risks.

\section{Expected effects of the 2005 pension reform}

\section{Outlook of the pension system before the reform}

One of the main determinants of future pension expenditures is demographics, both in terms of the number of working-age citizens who pay the contributions and the number of retirees who get the benefits. Figure 1 depicts both the old-age dependency ratio (based on the population projection of Statistics Finland) and the corresponding projected private sector pension expenditures/wage bill ratio before the reform in Finland. Expenditure growth is dampened by the fact that the ongoing strong improvement in the educational structure of the Finnish population will mitigate the effects of low fertility on the total wage bill. Since part of the future pensions are financed from the accrued capital funds, the corresponding projected contributionrate increase (about 9 percentage points) is somewhat smaller than the increase in expenditures (about 14 percentage points) in the long term. This expected increase in the contribution rate was one of the main reasons for the pension reform.

\section{Simulation results in the case of the expected demographic scenario}

We simulated the effects of the pension reform by using the model described in the previous section. The model provides us with results concerning macroeconomic and pension system variables, as well as the relative positions of different birth cohorts and educational groups. The underlying population projection was produced by Statistics Finland. $^{13}$

\footnotetext{
${ }^{13}$ Statistics Finland (2001).
} 
Numerical analysis and the interpretation of the simulation results require some grouping of the elements of the reform described above. In our analysis, the reform is divided into four parts, as follows:

Part I: Changes in accrual rates, moving from the current model to the "career model", and the changes in indexation.

Part II: Longevity adjustment of pension benefits.

Part III: All effects of the reform that come in the form of postponed retirement, either due to the limited eligibility to and abolishment of some early pension schemes or due to the assumed incentive effects of the other parts of the reform.

Part IV: Temporary increase in funding in 2003-2013 and prefunding of the excess contributions of the employees older than 52 years.

The macroeconomic outcomes of the reform are described in Table 1 as per cent changes. Higher retirement age dominates the results. Employment, production and investment increase by about 5 per cent and private consumption by almost 4 per cent during the next 50 years. This supply-driven expansion of the economy increases exports, but since export demand is price-elastic, the terms of trade must deteriorate somewhat. A closer look at the result in stages shows minor effects from Parts I and II, both generated mainly by the timing of consumption. In Part I, smoothing consumption over time requires higher spending by elderly households. In contrast, the need for higher saving is evident in Part II of the reform, which generates lower future pensions due to the longevity adjustment. The additional funding in Part IV shifts reserves into the future, which can be observed by looking at the time paths of wages and consumption.

The effect of the reform on pension expenditures, contributions and the prefunded amount is depicted in Table 2. The next few decades are dominated by a reduction in expenditures and an increase in the wage bill, both due to postponed retirement. After that the expenditures are restrained mainly by the longevity adjustment. Contribution rates deviate from the expenditure numbers mainly due to additional prefunding. It has been agreed earlier that the future increases in the contribution rate will be split evenly between the labour market parties.

The small overall changes in the prefunding rate hide two opposite effects. The higher retirement age reduces the funding rate, because the additional labour supplied occurs mostly during the last years of working life, when prefunding is no longer applied. This loss in prefunding is balanced by the agreed additional prefunding described in Part IV.

Table 3 presents the changes in the actuarity ratio resulting from the different parts of the reform. The actuarity ratio measures the gains and losses of various generations by changes in lifetime pension benefits and contributions. The effects are calculated for three educational groups. Future generations and the youngest current workers mainly lose from Part I of the reform. Higher accruals mean higher pensions but also higher contributions. Part I means expanding a mostly pay-as-you-go system, and the gain of the initial winners is paid by future cohorts. Currently working generations, excluding the youngest, are the winners. Those already retired are affected only due to changes in prices.

There are differences between educational groups. The cohorts with only basic schooling retire earlier than other groups, and thus benefit less from the higher accrual rates for those older than 52 and 62 years. They are hit hardest by the new timing of 
Table 1 Macroeconomic effects of the pension reform, per cent

\begin{tabular}{|c|c|c|c|c|c|c|c|}
\hline & Employment & $\begin{array}{c}\text { Private } \\
\text { production }\end{array}$ & Investment & $\begin{array}{c}\text { Priv. } \\
\text { consumption }\end{array}$ & Wage rate & $\begin{array}{l}\text { Consumer } \\
\text { prices }\end{array}$ & $\begin{array}{c}\text { Terms of } \\
\text { trade }\end{array}$ \\
\hline \multicolumn{8}{|c|}{ Part I } \\
\hline 2005 & 0.07 & 0.04 & 0.06 & 0.70 & 0.17 & 0.09 & 0.13 \\
\hline 2010 & 0.04 & 0.03 & -0.11 & 0.62 & 0.19 & 0.11 & 0.15 \\
\hline 2020 & -0.07 & -0.09 & -0.21 & 0.30 & -0.30 & 0.08 & 0.12 \\
\hline 2030 & -0.14 & -0.15 & -0.15 & 0.00 & -0.55 & 0.04 & 0.06 \\
\hline 2040 & -0.06 & -0.11 & -0.10 & -0.16 & -0.51 & 0.02 & 0.03 \\
\hline 2050 & 0.06 & -0.02 & -0.04 & -0.24 & -0.52 & -0.04 & -0.06 \\
\hline \multicolumn{8}{|c|}{ Part II } \\
\hline 2005 & 0.04 & 0.02 & -0.12 & -0.44 & -0.16 & -0.07 & -0.11 \\
\hline 2010 & 0.01 & -0.02 & -0.07 & -0.47 & -0.16 & -0.09 & -0.13 \\
\hline 2020 & -0.01 & -0.03 & 0.01 & -0.47 & 0.05 & -0.10 & -0.14 \\
\hline 2030 & 0.02 & 0.01 & 0.08 & -0.37 & 0.41 & -0.09 & -0.12 \\
\hline 2040 & 0.01 & 0.03 & 0.14 & -0.21 & 0.80 & -0.06 & -0.08 \\
\hline 2050 & 0.02 & 0.07 & 0.19 & 0.04 & 1.24 & -0.01 & -0.02 \\
\hline \multicolumn{8}{|c|}{ Part III } \\
\hline 2005 & 0.19 & 0.09 & 2.24 & 2.25 & 0.82 & 0.29 & 0.41 \\
\hline 2010 & 1.86 & 1.40 & 3.22 & 2.58 & 0.11 & 0.05 & 0.08 \\
\hline 2020 & 4.66 & 3.80 & 4.68 & 3.41 & -1.51 & -0.61 & -0.87 \\
\hline 2030 & 4.17 & 4.25 & 4.38 & 3.48 & -1.05 & -0.72 & -1.03 \\
\hline 2040 & 4.36 & 4.60 & 4.66 & 3.66 & -1.23 & -0.85 & -1.21 \\
\hline 2050 & 4.67 & 4.99 & 4.81 & 3.79 & -1.44 & -0.99 & -1.41 \\
\hline \multicolumn{8}{|c|}{ Part IV } \\
\hline 2005 & -0.05 & -0.02 & -0.13 & -0.76 & -0.53 & -0.02 & -0.04 \\
\hline 2010 & -0.04 & -0.04 & -0.02 & -0.68 & -0.50 & -0.05 & -0.07 \\
\hline 2020 & 0.03 & 0.02 & 0.07 & -0.30 & -0.17 & -0.06 & -0.08 \\
\hline 2030 & 0.02 & 0.03 & 0.08 & -0.05 & 0.04 & -0.04 & -0.05 \\
\hline 2040 & 0.02 & 0.05 & 0.08 & 0.17 & 0.18 & -0.01 & -0.02 \\
\hline 2050 & 0.00 & 0.04 & 0.05 & 0.31 & 0.26 & 0.02 & 0.03 \\
\hline \multicolumn{8}{|c|}{ Parts $I-I V$} \\
\hline 2005 & 0.26 & 0.13 & 2.05 & 1.75 & 0.30 & 0.28 & 0.40 \\
\hline 2010 & 1.87 & 1.36 & 3.02 & 2.05 & -0.37 & 0.02 & 0.03 \\
\hline 2020 & 4.61 & 3.70 & 4.56 & 2.93 & -1.93 & -0.68 & -0.97 \\
\hline 2030 & 4.07 & 4.14 & 4.39 & 3.05 & -1.15 & -0.80 & -1.14 \\
\hline 2040 & 4.32 & 4.57 & 4.79 & 3.45 & -0.75 & -0.90 & -1.28 \\
\hline 2050 & 4.75 & 5.07 & 5.01 & 3.89 & -0.46 & -1.02 & -1.46 \\
\hline
\end{tabular}

The years in the table refer to the first year of a five-year period, for example, 2000 means the average for the years 2000-2004. The results in Part I describe the per cent changes from the levels under the old system, and in Part II-Part IV the changes from the previous part, for example, Part II is implemented after Part I and the table describes the difference. The results add up, with rounding, to the total effect in Parts I-IV.

the index change: the 20-80 index takes effect immediately after retirement instead of at the age of 65 as in the current system. The index timing effect is smaller for better educated groups, who retire later and thus also benefit from the higher accrual rates. In the long term, people with a medium-level education lose the most. We have 
The Geneva Papers on Risk and Insurance - Issues and Practice

84

Table 2 The effects of the reform on pension variables

\begin{tabular}{|c|c|c|c|}
\hline & $\begin{array}{c}\text { Expenditures/wage bill, } \\
\text { per cent }\end{array}$ & $\begin{array}{c}\text { Contributions/wage bill, } \\
\text { per cent }\end{array}$ & $\begin{array}{c}\text { Funded amount/wage bill, } \\
\text { per cent }\end{array}$ \\
\hline \multicolumn{4}{|c|}{ Part I } \\
\hline 2005 & 0.0 & 0.1 & 0.0 \\
\hline 2010 & 0.4 & 0.4 & 0.2 \\
\hline 2020 & 1.9 & 1.7 & 0.3 \\
\hline 2030 & 2.4 & 2.3 & 0.2 \\
\hline 2040 & 1.8 & 1.9 & -0.5 \\
\hline 2050 & 1.4 & 1.4 & -1.0 \\
\hline \multicolumn{4}{|c|}{ Part II } \\
\hline 2005 & 0.0 & 0.0 & 0.0 \\
\hline 2010 & -0.1 & -0.1 & 0.2 \\
\hline 2020 & -0.6 & -0.6 & 0.1 \\
\hline 2030 & -1.5 & -1.4 & -0.4 \\
\hline 2040 & -2.2 & -2.1 & -0.8 \\
\hline 2050 & -3.1 & -3.0 & -1.0 \\
\hline \multicolumn{4}{|c|}{ Part III } \\
\hline 2005 & -0.8 & -1.3 & 0.0 \\
\hline 2010 & -1.9 & -2.3 & -4.1 \\
\hline 2020 & -3.4 & -3.5 & -12.2 \\
\hline 2030 & -2.4 & -2.1 & -14.9 \\
\hline 2040 & -2.2 & -2.0 & -15.0 \\
\hline 2050 & -2.3 & -2.1 & -15.9 \\
\hline \multicolumn{4}{|c|}{ Part IV } \\
\hline 2005 & 0.05 & 1.25 & 0.00 \\
\hline 2010 & 0.00 & 0.96 & 7.00 \\
\hline 2020 & -0.11 & 0.13 & 14.07 \\
\hline 2030 & -0.11 & -0.23 & 17.64 \\
\hline 2040 & -0.05 & -0.41 & 18.21 \\
\hline 2050 & 0.02 & -0.43 & 17.30 \\
\hline \multicolumn{4}{|c|}{ Parts $I-I V$} \\
\hline 2005 & -0.8 & 0.1 & 0.0 \\
\hline 2010 & -1.7 & -1.1 & 3.2 \\
\hline 2020 & -2.2 & -2.3 & 2.2 \\
\hline 2030 & -1.7 & -1.6 & 2.5 \\
\hline 2040 & -2.6 & -2.7 & 2.0 \\
\hline 2050 & -3.9 & -4.0 & -0.5 \\
\hline
\end{tabular}

The years in the table refer to the first year of a five-year period, for example, 2000 means the average for the years 2000-2004 except for the funded amount that describes the situation at the beginning of the first year. The results in Part I describe the percentage point changes from the levels under the old system, and in Part II-Part IV the changes from the previous part, for example, Part II is implemented after Part I and the table describes the difference. The results add up, with rounding, to the total effect in Parts I-IV.

assumed that they have longer work relations than those with only basic education, and, on average, relatively high earnings in later stages of their careers. They lose, relatively speaking, since their income affects the pension more evenly during the 
Table 3 Actuarity rate effects from the pension reform, by cohort and educational group

\begin{tabular}{|c|c|c|c|c|c|c|c|c|c|c|}
\hline Birth year of cohort & 1940 & 1950 & 1960 & 1970 & 1980 & 1990 & 2000 & 2010 & 2020 & 2030 \\
\hline \multicolumn{11}{|l|}{ Part I } \\
\hline Basic schooling & 0.3 & 2.7 & 8.4 & 1.2 & -3.3 & -1.2 & -0.9 & -0.3 & 0.2 & 0.3 \\
\hline Medium level & 0.4 & 6.2 & 6.6 & -0.9 & -4.6 & -2.9 & -2.4 & -1.8 & -1.4 & -1.3 \\
\hline High education & 0.6 & 11.2 & 9.3 & 4.2 & -0.3 & -0.1 & 0.2 & 0.6 & 0.9 & 0.9 \\
\hline Weighted & 0.4 & 6.0 & 7.6 & 1.0 & -2.8 & -1.5 & -1.1 & -0.6 & -0.2 & -0.2 \\
\hline \multicolumn{11}{|l|}{ Part II } \\
\hline Basic schooling & -0.2 & -2.1 & -4.7 & -5.2 & -4.6 & -3.8 & -1.4 & 0.5 & 1.5 & 2.0 \\
\hline Medium level & -0.1 & -2.1 & -4.6 & -4.9 & -4.5 & -3.7 & -1.5 & 0.2 & 1.1 & 1.5 \\
\hline High education & -0.1 & -2.0 & -4.2 & -4.7 & -4.3 & -3.6 & -1.6 & -0.1 & 0.6 & 0.9 \\
\hline Weighted & -0.1 & -2.1 & -4.5 & -4.9 & -4.4 & -3.7 & -1.5 & 0.1 & 0.9 & 1.2 \\
\hline \multicolumn{11}{|l|}{ Part III } \\
\hline Basic schooling & -0.4 & -4.2 & -6.4 & -3.8 & -1.3 & -0.7 & -1.5 & -2.3 & -2.3 & -2.4 \\
\hline Medium level & -0.4 & -3.5 & -5.2 & -3.1 & -1.0 & -0.4 & -1.2 & -1.9 & -2.0 & -2.0 \\
\hline High education & -0.2 & -1.3 & -0.5 & 1.6 & 3.0 & 3.0 & 1.9 & 1.5 & 1.4 & 1.3 \\
\hline Weighted & -0.4 & -3.3 & -4.2 & -1.7 & 0.6 & 1.2 & 0.3 & -0.3 & -0.3 & -0.4 \\
\hline \multicolumn{11}{|l|}{ Parts IV } \\
\hline Basic schooling & -0.3 & -1.6 & -2.2 & -1.3 & -0.4 & 0.7 & 1.2 & 1.2 & 1.1 & 1.0 \\
\hline Medium level & -0.3 & -2.0 & -2.1 & -1.1 & -0.3 & 0.7 & 1.2 & 1.2 & 1.0 & 0.9 \\
\hline High education & -0.2 & -2.3 & -1.8 & -1.0 & -0.2 & 0.9 & 1.1 & 1.1 & 1.0 & 0.9 \\
\hline Weighted & -0.3 & -1.9 & -2.0 & -1.1 & -0.3 & 0.8 & 1.2 & 1.1 & 1.0 & 0.9 \\
\hline \multicolumn{11}{|l|}{ Parts $I-I V$} \\
\hline Basic schooling & -0.5 & -5.1 & -4.9 & -9.1 & -9.7 & -5.0 & -2.6 & -0.8 & 0.5 & 0.8 \\
\hline Medium level & -0.4 & -1.4 & -5.2 & -10.0 & -10.4 & -6.3 & -4.0 & -2.4 & -1.2 & -0.9 \\
\hline High education & 0.1 & 5.5 & 2.8 & 0.2 & -1.7 & 0.2 & 1.7 & 3.0 & 3.9 & 3.9 \\
\hline Weighted & -0.4 & -1.3 & -3.2 & -6.7 & -6.9 & -3.2 & -1.1 & 0.3 & 1.4 & 1.5 \\
\hline
\end{tabular}

The years in the table refer to the first year of a five-year period, for example, 2000 means the average for the years 2000-2004. The results in Part I describe the per cent changes from the levels under the old system, and in Part II-Part IV the changes from the previous part, for example Part II is implemented after Part I and the table describes the difference. The results add up, with rounding, to the total effect in Parts I-IV.

whole career. People with high education will also suffer from this feature in relative terms, but they will benefit more from the higher accrual rates because, on average, they have the highest effective retirement age.

The effects of the longevity adjustment are rather clearcut. Current working cohorts, whose pensions will be cut by the adjustment, lose because they do not have time to benefit from the decline in contributions in the long run. The losses are largest for those born in the 1960s, 1970s and 1980s. Generations born after the year 2010 will benefit from this part of the reform. Their pensions will be smaller but the decline in contributions more than compensates for this.

The actuarity losses due to Part III of the reform are larger for those with only basic schooling, because we assume that their retirement is postponed more than that of other groups. This assumption was made because the less-educated typically used 
more of the early retirement routes, which were abolished or restricted. The highest education group is assumed to postpone retirement the least. The cohorts born in 1950s and 1960s who have acquired a medium-level education seem also to be hit hard from the postponement effect. This is due to the assumption of the timing of postponement.

Part IV hurts those who pay contributions when funding is increased and benefits those who pay contributions during the 2030s. The effects are, however, small.

Looking at the overall actuarity effects, we note that the winners are old workers especially with high education, and also future workers. The losers are current workers with only a basic or medium-level education.

The wage and price changes may have important welfare consequences over and above the changes in the actuarity rates. Specifically, postponing retirement increases labour supply and reduces consumer prices, increasing the purchasing power of income and savings, and resulting in sizeable increases in welfare. On the other hand, the overall effects of the reform on lifetime consumption are much smaller than on contributions to and benefits from the pension system. The measure does not consider the loss of welfare due to reduced leisure. Note also that risk aspects are missing from the winner-loser analysis, because the current model does not include risks and uncertainties.

\section{Demographic risks}

The analysis above is based on one "official" demographic projection, made by Statistics Finland. ${ }^{14}$ Such a projection is a summary of knowledge of past trends and likely future developments. Given that the predictive value of our current knowledge decreases rapidly as we look further into the future, a characterisation of the increasing uncertainty is needed. This is provided by stochastic population forecasts, which are particularly useful in informing the users about the possibility of future developments that are not foremost in the minds of policy planners. ${ }^{15}$ Thus, to get a wider perspective on how the pension reform will cope with different demographic outcomes, we resort to stochastic simulations of the future Finnish population. ${ }^{16}$ This is important especially as the reform includes longevity adjustment, an element which reacts directly to a specific feature of the future demographic development.

The following scatter plots describe the pension situation in Finland for the years 2030 and 2050. Each of the dots represents one population path. A model solution for some of the 300 population paths could not be obtained, and thus there are 284 dots for the old system and 295 for the new. The replacement rate is measured here by the ratio of average pension income of 65-69-year-old persons, with a medium-level education, to the average wage income of 20-59-year-old persons with the same education level. The average pension income combines pensions that may have started

\footnotetext{
14 Ibid.

${ }^{15} \mathrm{~A}$ recent set of stochastic population forecasts, together with a description of the method used to compute the forecasts for 18 European countries is available at http://www.stat.fi/tup/euupe/.

${ }^{16}$ Alho (2002).
} 
as disability pensions for some young or middle-aged persons and then changed to oldage pensions, and pensions that have started directly as old-age pensions for those at eligible ages. Thus, the replacement rate here does not describe the pension of a fullcareer worker relative to his last or average wage income.

The upper part of Figure 2 describes the outcomes under the old system. There is a negative correlation between replacement and contribution rates across different population paths. The reason for this is that high contribution rates occur when the labour force is small. This raises real wages, but pensions increase less because they are only partially indexed to wages. Another observation is that contribution rates vary more than replacement rates, which is not surprising in a defined-benefit system.

The lower part of Figure 2 describes the outcomes under the reform effective as of 1st January, 2005. The negative correlation between replacement and contribution rates becomes steeper. Contributions vary less because of the longevity adjustment of benefits and the postponement of the retirement age. Replacement rates vary more
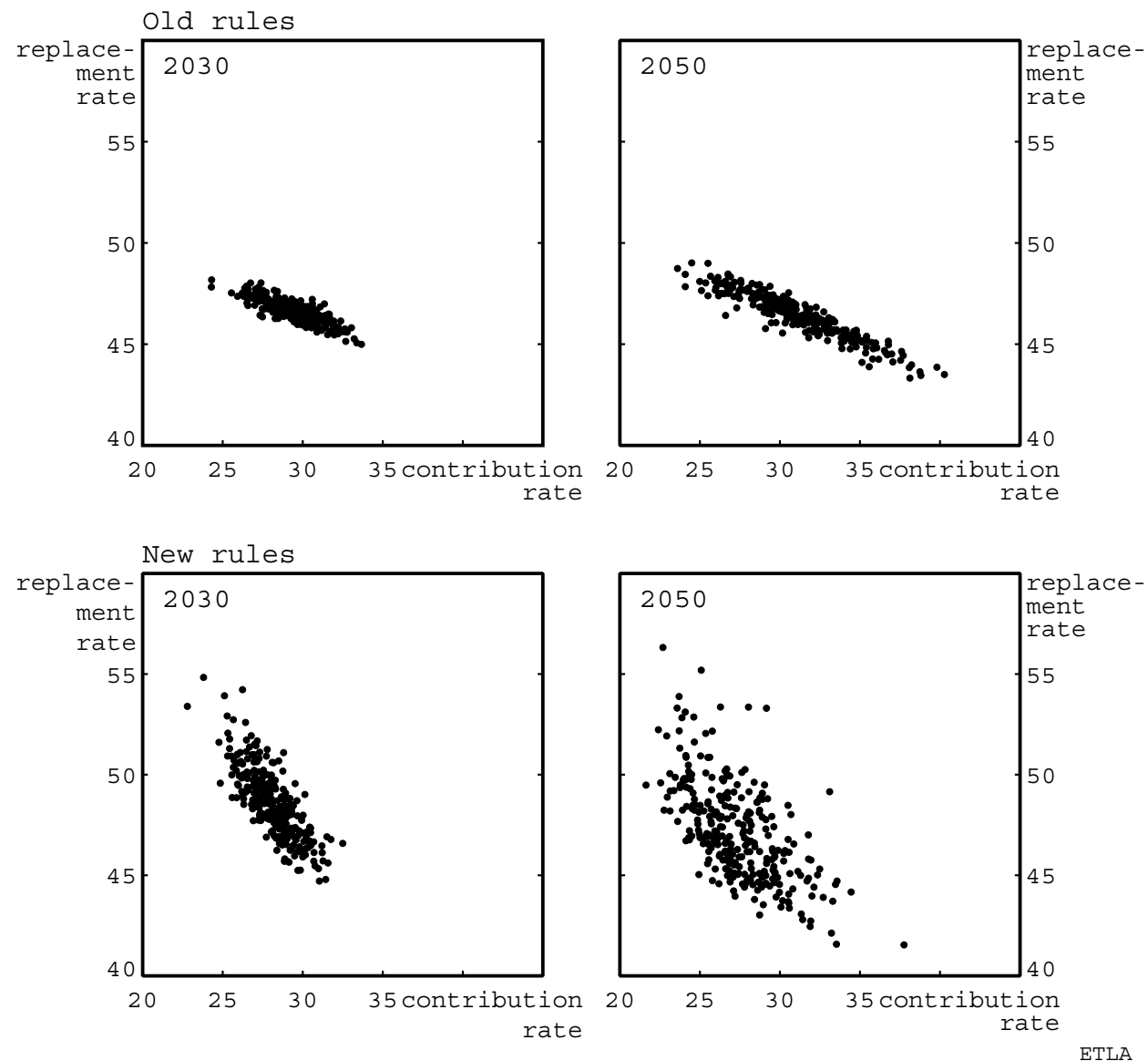

Figure 2. Pension contribution and replacement rates in 2030 and 2050. 
also because of the longevity adjustment and in addition because of changes in indexation, especially the timing of the change in the relative weights of wages and prices in the index. For these same reasons, the correlation between replacement and contribution rates has also become looser.

Figure 3 concentrates on the effects of the reform. If, in the upper part, the dot is above the diagonal, then the replacement rate in that population path is higher after the reform than it would have been without the reform. This usually seems to be the case in 2030: the reform increases replacement rates. The lower part shows that the reform decreases the contribution rates (all the dots are below the diagonal), and the reduction is bigger, the higher the rate that would have occurred without the reform. In 2050, the situation is different for replacement rates; in almost 40 per cent of population paths, the replacement rate declines. The contribution rate is smaller in all cases. Thus, the reform clearly shifts risks to pensioners, even though in most cases it increases replacement rates besides decreasing contribution rates.
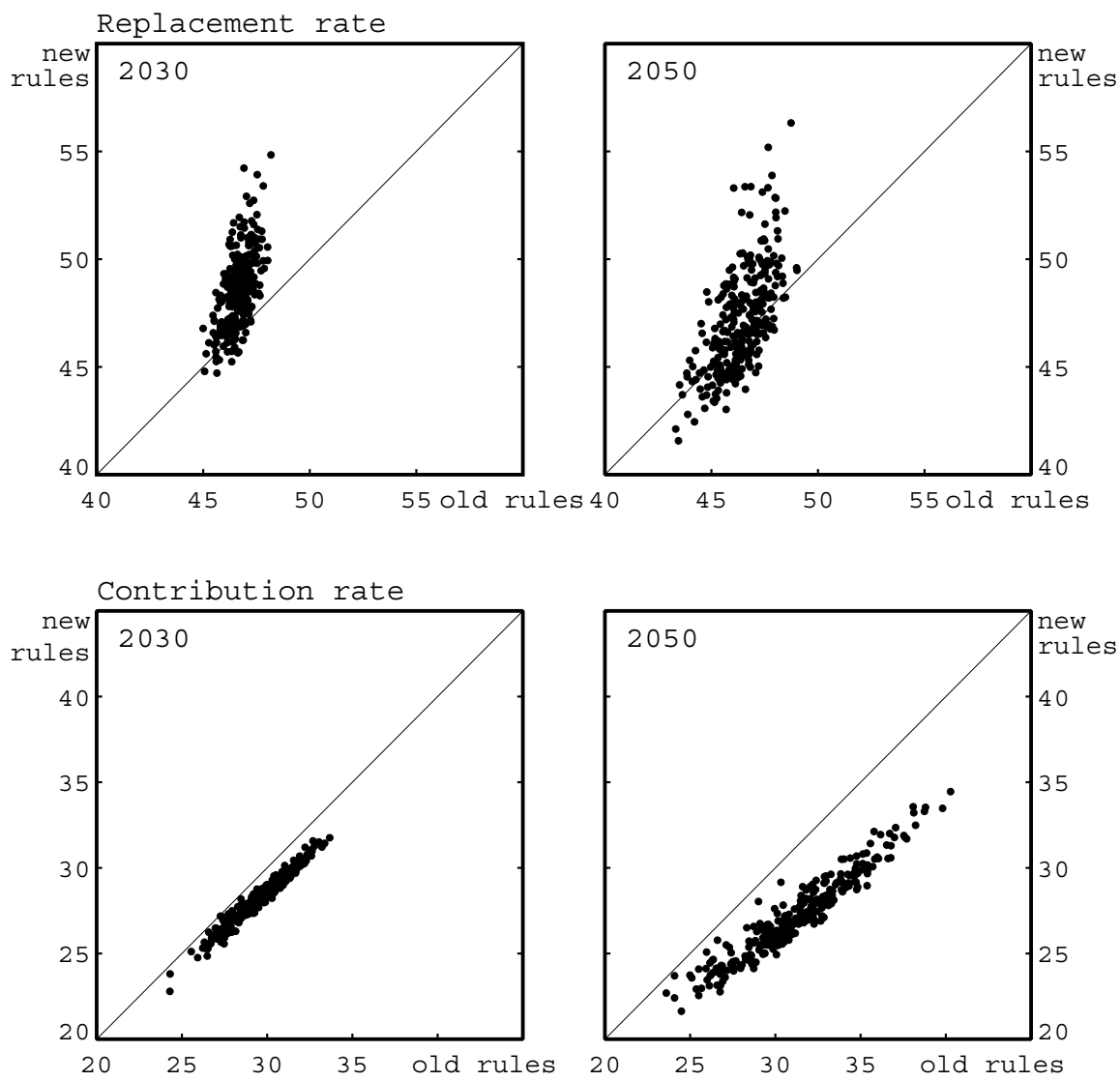

Figure 3. Pension contribution and replacement rates under old and new rules. 

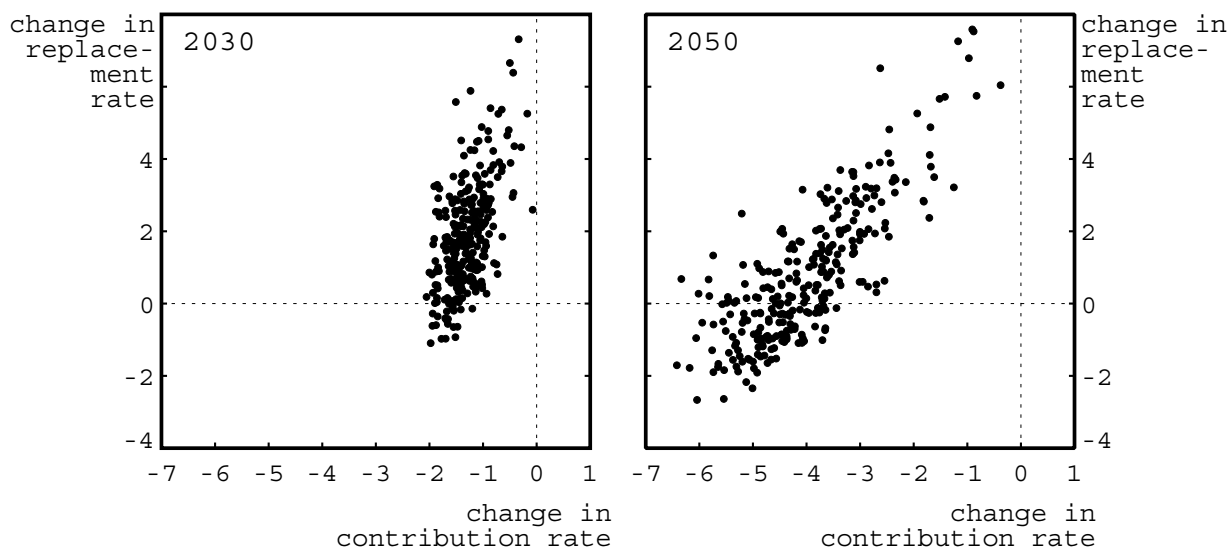

Figure 4. Reform's effects on pension contribution and replacement rates in 2030 and 2050, per cent-points.

This rather favourable outcome is, to a large extent, a consequence of the assumed increase in the effective retirement age.

Figure 4 shows how the reform jointly affects the contribution and replacement rates. In 2030, the outcomes are mostly beneficial: contribution rates decline, whereas replacement rates increase or do not fall significantly. In 2050, the overall image is still favourable but replacement rates fall more and more often. Large decreases in contribution rates are difficult to achieve without decreases in replacement rates, even though the retirement age increases.

\section{Concluding remarks}

We have analysed the Finnish private sector pension reform that took effect on 1 st January, 2005. The main elements of this wide reform package are (i) moving from individual employment contracts to a career model in calculating pension rights, with changes in accrual rates and indexation rules, and abolishment of the benefit ceiling; (ii) longevity adjustment of benefits for those reaching the age of 62 in 2010 and after; (iii) choice of retirement for old-age pension between ages 62 and 68, changes in early retirement eligibility limits, and other measures aiming at postponing retirement; (iv) changes in prefunding and (v) accrual of benefit rights for some non-salary income. Our analysis considers the first four elements of the reform.

The reform appears successful in many respects. It simplifies the private sector pension system and makes it a model that other pension systems in Finland will converge to. It curbs the increase in contribution rate without endangering the adequacy of replacement rates. The increase in labour supply due to a higher retirement age will have additional beneficial welfare effects outside the pension system. According to our analysis, the new system responds well also to uncertain future demographics. In population paths where the contribution rates under the old 
system would increase the most from the current level, the reform curb these increases the most.

Despite this apparent success of the reform, there remains a serious doubt of its adequacy. ${ }^{17}$ Contribution rates are still expected to rise by several percentage points, even though the retirement age is assumed to increase. And this assumption may be a poor forecast. Although the reform encourages postponing retirement, other factors such as increasing wealth may well prove more influential. If the effective retirement age rises less than assumed, the contribution base - the wage bill - will also grow less, and contribution rates must increase more to meet the benefit bill, or the benefits must be cut.

One obvious, but in practice quite complicated, extension to the analysis would be adding retirement decisions to the model. Another interesting aspect would be to analyse the sustainability of the reformed pension system, given stochastic variation in some main economic factors, such as labour productivity and the yield of the pension funds.

\section{References}

Alho, J.M. (2002) The population of Finland in 2050 and beyond, ETLA, Discussion paper No. 826, Helsinki.

Alho, J.M. (2003) Predictive distribution of adjustment for life expectancy change, Finnish Centre for Pensions Working Papers 3, Helsinki.

Alho, J.M., Jensen, S.E.H., Lassila, J. and Valkonen, T. (2005) 'Controlling the effects of demographic risks: the role of pension indexation schemes', Journal of Pension Economics and Finance 4(2): 139-153.

Auerbach, A.J. and Kotlikoff, L.J. (1987) Dynamic Fiscal Policy, Cambridge: Cambridge University Press, U.K.

Biström, P., Klaavo, T., Risku, I. and Sihvonen, H. (2004) Eläkemenot, -maksut ja -rahastot vuoteen 2075 , Finnish Centre for Pensions, Reports 2004:36, Helsinki.

Börsch-Supan, A. (2005) The 2005 Pension Reform in Finland, Finnish Centre for Pensions Working papers 2005:1, Helsinki.

European Commission (2004) 'Pension Policy and Pension Reform', Special Eurobarometer (January).

Fehr, H. (2000) 'Pension reform during the demographic transition', Scandinavian Journal of Economics 102(3): 419-444.

Hietaniemi, M. and Vidlund, M. (eds.) (2003) The Finnish Pension System, Helsinki: The Finnish Centre for Pensions, http://www.etk.fi.

Ilmakunnas, S. and Takala, M. (2005) 'Promoting employment among ageing workers: lessons from successful policy changes in Finland', The Geneva Papers on Risk and Insurance - Issues and Practice 30(4): 674-692.

Kotlikoff, L., Smetters, K. and Walliser, J. (1998) 'Social security: privatization and progressivity', American Economic Review 88(2): 137-141.

Lassila, J. (2004) 'Bargaining on pensions: the Finnish Pension Reform of 2001-2002', in H. Piekkola and K. Snellman (eds.) Collective Bargaining and Wage Formation Performance and Challenges, Heidelberg: Physica-Verlag.

Lassila, J. and Valkonen, T. (2003) 'Ageing, demographic risks and pension reform,' in M. Weale (ed.) Social Security and Pension Reform, NIESR Occasional paper, No. 56.

Lindell, K. (1999) Life expectancy increases - what will happen to retirement age? (in Finnish), Working group memorandum, Finnish Centre for Pensions, Reports 1999:18, Helsinki.

Statistics Finland (2001) Väestöennuste kunnittain 2001-2030, Väestö 2001:11, Helsinki.

${ }^{17}$ See also Börsch-Supan (2005). 


\section{Appendix: FOG Model}

FOG is an Auerbach-Kotlikoff-type, perfect foresight numerical overlapping generations model. There are five sectors: households, enterprises, a government, a pension fund and a foreign sector. The labour, goods and capital markets are competitive and prices balance supply and demand period-by-period. There is no money or inflation in the model. Households and firms are forward-looking decisionmakers.

The model is adjusted to imitate the Finnish economy by a process of calibration. First, parameters for household behaviour (e.g., preference for leisure) and production technology (e.g., substitutability of capital and labour) are extracted from the economic literature and used to generate numerical versions of those model equations, describing the dynamics of the economy. The current and future household cohorts are then aggregated using population statistics and forecasts. Finally, the model is scaled so that it produces macroeconomic, public sector and household statistics for recent years.

\section{Household behaviour}

Households maximise the utility from consumption and leisure in different periods and the bequest that they give. The life-cycle plan for a household starting its work life at time $t=1$ is the solution to the following maximisation problem subject to the periodic utility function (2), lifetime budget constraint (3) as well as the determination of gross labour incomes (4), pensions $g^{Z}$, and the discount factor (5):

$$
\begin{gathered}
\operatorname{Max}_{c, l, B} U_{t_{0}}=E \sum_{i=1}^{T_{0}} \frac{1}{1-\gamma^{-1}} S_{1, i} \frac{U_{t_{0}, i}^{1-(1 / \gamma)}}{(1+\delta)^{i-1}}+\frac{1}{1-\gamma^{-1}} S_{1, i} \mu \frac{B_{T_{0}}^{1-(1 / \gamma)}}{(1+\delta)^{T_{0}-1}} \\
U_{t_{0}, i}=\left(c_{t_{0}, i}^{1-1 / \rho}+\alpha l_{t_{0}, i}^{1-1 / \rho}\right)^{(1-1 / \rho)^{-1}} \\
\sum_{i=1}^{T_{0}} g_{t_{0}, i}^{w}\left(1-\tau_{t}^{e}-\tau_{t}^{w}\right) R_{t}+\sum_{i=1}^{T_{0}} g_{t_{0}, i}^{Z}\left(1-\tau_{t}^{w}\right) R_{t}+R_{t_{B}} B_{t_{B}}+\sum_{i=1}^{T_{0}} s_{t_{0}, i} \\
+\sum_{i=1}^{T_{0}} s_{t_{0}, i}^{Z}=\sum_{i=1}^{T_{0}} c_{t_{0}, i} p_{t_{0}, i}^{C}\left(1+\tau_{t}^{C}\right) R_{t}+R_{T_{0}} B_{T_{0}} \\
g_{t_{0}, i}^{w}=\left(1-l_{t_{0}, i}\right) l_{t_{0}, i}^{\max } e_{t} w_{t} \\
R_{t}=S_{1,1 t}(1+r)^{1-t}
\end{gathered}
$$

Households consider the possibility of early death by discounting future consumption and incomes by a factor that includes both the interest rate and the age-specific survival probability. The variable $c_{t}$ describes consumption, $p_{t}^{C}$ its price, $l_{t}$ is leisure, 
and of the constant parameters $\gamma$ is the elasticity of intertemporal substitution, $\delta$ is the rate of time preference and $\rho$ is the elasticity of substitution between consumption and leisure. Households receive a bequest $B_{i}$ at the age of $i$ and give a bequest $B_{T}$ before dying. The parameter $\mu$ determines the strength of the joy-of-giving bequest motive. The aggregate amount of the generation-specific transfers $S_{t}$ is determined to balance the revenues and expenditures of the central government. A life-cycle plan is made at the age of 20, and people plan to retire at the age of $T_{w}+1$. The budget constraint (3) says that discounted lifetime wage income and pension income equals discounted consumption expenditure. The term $l_{t_{0}, i}^{\max }$ gives the exogenous share of people in cohort born at $t_{0}$ in age $i$ that have not retired yet. The terms $\tau^{w}$ and $\tau^{C}$ are income tax and value added tax parameters. We have excluded the capital income taxes from this presentation to simplify the expressions.

\section{The pension system after the reform}

The pensions can be thought of as consisting of both disability pensions and old-age pensions. The pension income for each cohort depends on pensions that have started at different ages. $z_{t_{0}, i}^{r}$ denotes a pension that a cohort born at $t_{0}$ receives at age $j$ and has first received at age $r$.

$$
g_{t_{0}, i}^{Z}=\sum_{r=2}^{i} z_{t_{0}, i}^{r}
$$

In the new system, the length of employment contract periods does not affect the pension at all. The pension rights accrue in each work period. In addition, if, due to disability, the last working age is $r-1$, the pensioner will get compensation for lost future accruals.

$$
\begin{gathered}
z_{t_{0}, i}^{\text {accrued }}=k_{t_{0}, i} g_{t_{0}, i}^{r e f} \\
z_{t_{0}, r-1}^{\text {future }}=k_{t_{0}, r-1}^{\text {future }} g_{t_{0}, r-1}^{r e f}
\end{gathered}
$$

where

$$
g_{t_{0}, i}^{r e f}=\left(1-l_{t_{0}, i}\right)\left(l_{t_{0}, i}^{\max }\right) e_{i} w_{t_{0}+i-1}\left(1-\tau_{t_{0}+i-1}^{e}\right)
$$

The accruals in different periods are indexed to other periods by

$$
I\left(t_{1}, t_{2}, \lambda(t)\right)=\prod_{t=t_{1}}^{t_{2}-1}\left(\frac{\left(1-\tau_{t+1}^{e}\right) w_{t+1}}{\left(1-\tau_{t}^{e}\right) w_{t}}\right)^{\lambda(t+1)}\left(\frac{p_{t+1}^{C}}{p_{t}^{C}}\right)^{1-\lambda(t+1)}
$$

Thus, the first pension is

$$
\begin{aligned}
z_{t_{0}, r}^{r}= & \sum_{i=1}^{r-1} z_{t_{0}, i}^{\text {accrued }} I\left(t_{0}+i-1, t_{0}+r-2, \lambda_{w}\right) I\left(t_{0}+r-2, t_{0}+r-1, \lambda_{z}\right) \\
& +z_{t_{0}, r-1}^{\text {future }} I\left(t_{0}+r-2, t_{0}+r-1, \lambda_{z}\right)
\end{aligned}
$$

After receiving the disability pension for five years, there is a one-time level increase $m$ in the pension. This increase is 21 per cent for a person aged 26 or less, and smaller for 
older persons, so that those aged 56 or more get no increase.

$$
z_{t_{0}, i}^{r}=m_{t_{0}, r+1} z_{t_{0}, r}^{r} I\left(t_{0}+r-1, t_{0}+i-1, \lambda_{z}\right)
$$

where $i>r$.

The actual equations of the simulation model are the first-order conditions derived from the optimisation problem.

\section{Longevity adjustment}

The pensions are adjusted for increasing life expectancy simply by taking into account the increasing longevity in the value of the annuity. The adjustment coefficient is a ratio of two present values of a unit pension, calculated at two different periods. The present value of a unit pension, which begins in period $v$ and is calculated forward from age 62 (inside period 9), is as follows:

$$
a_{62}^{t_{0}+9}=0.6+\sum_{i=10}^{14}\left(1+r^{a}\right)^{9-i} S_{v-1,9, i}
$$

The present value of a unit pension is a discounted sum of terms generated during various retirement years. The terms have three parts. The first is the discounting factor in which the discount rate is $r^{a}$. The second describes longevity. The first subscript of the $S$ terms, $v$-1, demonstrates that life expectancy is evaluated using information available in the first period $v$, that is, the observations from period $v-1$.

The longevity adjustment coefficient $E_{v 0}^{v}$ is a ratio of two $a$ numbers as follows.

$$
E_{t_{0}+9}^{2005-09}=a_{62}^{2005-09} / a_{62}^{t_{0}+9}
$$

Correspondingly, the pension of a person becoming 65 years old during period $v$ is

$$
z_{t_{0}, i}^{r}=E_{t_{0}+9}^{2005-09} m_{t_{0}, r+1} z_{t_{0}, r}^{r} I\left(t_{0}+r-1, t_{0}+i-1, \lambda_{z}\right) \text { when } i>9 r
$$

\section{Decision problem of the firms}

Firms choose the optimal amount of investment and use of labour to maximise the price of their shares. The market value of the firm is determined as a discounted sum of future dividends. The problem can be presented as maximising in the beginning of the period the dividends distributed during the period plus the value of the firm at the end of the period, subject to the amount of initial capital stock, the cash-flow equation of the firm, the CES production function, the accumulation condition of the capital stock, the determination of the firm's debt and the investment adjustment costs. Three of the four first-order conditions of the constrained optimisation are used as model equations, the fourth being the transversality condition.

\section{Markets}

The model includes four markets, which clear every period. In the labour market, firms demand labour according to the marginal productivity of labour rule. 
Households' aggregate labour supply is divided between public and private employment. The wage rate is determined by equating supply and demand in the labour market.

Firms are sole suppliers in the market for the domestic good. The product is used by other firms as part of the composite intermediate and investment goods, by households as part of the composite consumption good and by foreign agents. The demand of domestic agents and the prices of the composite goods are determined by a cost minimising procedure. Domestic demand for the fixed-price imported good is also determined by minimising the costs of the composite goods. The perfectly elastic supply adjusts to demand in this market. The fourth market is the capital market, in which savings and investments are balanced by the domestic interest rate. We use in the simulations a model version in which the interest rate is set equal to the rate in international capital markets. In this case, total saving is the sum of domestic savings and foreign portfolio investments.

The presentation above describes only the relevant parts of the model. The actual model includes, for example, a government with an intertemporal budget constraint, and trade and capital flows with the rest of the world.

\section{Actuarity ratio}

As an intergenerational measure of the connection between benefits and contributions, we define the following. The actuarity ratio is the ratio of a cohort's discounted benefits from the pension system to its discounted sum of payments to the pension system. The benefits include old-age pensions, denoted by $z$, and, combined into $s^{Z}$, disability and unemployment pensions and all other pensions from the earningsrelated pension system.

$$
A^{R}=\left(\sum_{t=1}^{T} s_{t}^{Z} R_{t}+\sum_{t=T_{W}+1}^{T} z_{t} R_{t}\right) /\left(\sum_{t=1}^{T_{W}} \tau_{t}^{l} g_{t} R_{t}\right)
$$

\section{About the Authors}

Jukka Lassila is Research Director at the Research Institute of the Finnish Economy (ETLA). He has studied pension policies and evaluated reforms in Finland and Lithuania. He was scientific coordinator in the EU 5th Framework research project "Demographic uncertainty and the sustainability of social welfare systems" and has published several articles within the field.

Tarmo Valkonen D.Sc. (econ.) is Head of Unit in Public finance and economic policy research at the Research Institute of the Finnish Economy (ETLA). His main research areas are taxation and economic aspects of population ageing. He has published articles on taxation, pension policy and funding of health care in several journals and other refereed international publications. 